\title{
Subcapsular left hepatic lobe hematoma: A potentially life-threatening post-ERCP complication
}

\author{
Alzubaidi A.M., Alshadadi A.A., Atta M.F., Alsareii S.A.
}

\section{ABSTRACT}

Endoscopic retrograde cholangiopancreatography (ERCP) is minimally invasive procedure commonly performed for biliary and pancreatic diseases. According to literature, the most common related complication are pancreatitis, post-sphincterotomy bleeding, perforation and cholangitis. This is rare and exceptional ERCP complication and only few cases have been reported. We report a case of rare post-ERCP complication, subcapsular liver hematoma that was diagnosed 16 hour post-ERCP in 28 -year-old lady with intra-abdominal collection, ultrasound guided drainage of suspected bile leak was done, but the drained fluid was bloody (blood mixed with bile), with total amount of $900 \mathrm{ml}$ in the first 36 hours. Patient received 2 units packed RBCs and she maintain her vital sign and hemoglobin $8.5 \mathrm{~g} / \mathrm{dl}$. Computed tomography scan of abdomen revealed a large left hepatic lobe subcapsular hematoma $16 \times 7 \times 12 \mathrm{~cm}$ with no active bleeding causing compression of the left hepatic vessels. On the basis of laboratory, clinical, and hemodynamic parameters the patient was hemodynamically stable. She was managed conservatively with only ultrasound

Alzubaidi A.M. ${ }^{1}$, Alshadadi A.A. ${ }^{1}$, Atta M.F. ${ }^{1}$, Alsareii S.A. ${ }^{2}$ Affiliations: ${ }^{1}$ King Khalid Hospital - Najran/Gastroenterology, Saudi Arabia; '²Faculty of Medicine, Surgical Department - Najran University, Saudi Arabia.

Corresponding Author: Dr. Ali Mothanna Saleh Al-zubaidi, Consultant Gastroenterology and Hepatology King Khalid hospital - Najran; Clinical Assistant Professor Faculty of Medicine/Najran University, Saudi Arabia; Email: dr_ali26@ yahoo.com

Received: 24 March 2017

Accepted: 09 May 2017

Published: 30 August 2017 guided drained of abdominal collection and no any radiological or surgical intervention needed for the hematoma.

Keywords: Endoscopic retrograde cholangiopancreatography, Post-ERCP complication, Subcapsular hematoma

\section{How to cite this article}

Alzubaidi AM, Alshadadi AA, Atta MF, Alsareii SA. Subcapsular left hepatic lobe hematoma: A potentially life-threatening post-ERCP complication. Int $\mathrm{J}$ Hepatobiliary Pancreat Dis 2017;7:32-35.

Article ID: 100071IJHPDAM2017

$* * * * * * * *$

doi: 10.5348/ijhpd-2017-71-CR-7

\section{INTRODUCTION}

Endoscopic retrograde cholangiopancreatography (ERCP) is one of the most frequently performed therapeutic procedures for biliary and pancreatic diseases. The ERCP-related complications around $2.5-9 \%$, with a mortality rate ranging from $0.6-1 \%[1]$. Post-ERCP pancreatitis, perforation, cholangitis and post-sphincterotomy bleeding are the most frequently described complications [2, 3]. Rare unexpected post-ERCP complication such as subcapsular hepatic hematoma was firstly described in 2000 [4].

Although it is rare and potentially life-threatening condition after ERCP. We report an unusual case of left hepatic lobe subcapsular hematoma after ERCP presenting with a drop in hemoglobin, tachycardia and intra-abdominal collection. 


\section{CASE REPORT}

A 28-year-old female was referred to us as a case of obstructive jaundice caused by common hepatic duct stricture misdiagnosed as choledocholithiasis by ultrasound abdomen. She was admitted for ERCP. Proper biliary drainage was done after dilatation of common hepatic duct stricture by dilator catheter up to 10 French with the placement of plastic stent of 10 French gauge, $10 \mathrm{~cm}$ length without immediate complications (Figure 1; arrow A), the second day after the procedure the patient complained of mild abdominal pain and fullness in the epigastric area. She developed tachycardia (pulse rate 115 beats per minute and blood pressure $100 / 60 \mathrm{mmHg}$ ) with a drop of hemoglobin of $2 \mathrm{~g} / \mathrm{dl}$ without melena or hematemesis.

Laboratory tests revealed a normal white blood cell count $8.5 \times 10^{9} / \mathrm{L}$ and drop in hemoglobin level from 9 $\mathrm{g} / \mathrm{dl}$ to $7 \mathrm{~g} / \mathrm{dL}$, platelets 243, INR 1.4, total bilirubin 214 umol/L, direct bilirubin 176 umol, AST 55 u/L, ALT 60 u/l, ALP 174 u/L, GGT $90 \mathrm{u} / \mathrm{L}$ and normal amylase level.

Abdominal ultrasound showed free fluid in the abdomen with a subscapular liver collection. Ultrasound guided drainage of suspected bile leak was done it drained (Figure 1; arrow B). Bloody fluid with a total amount of $900 \mathrm{ml}$ drained in the first 36 hours (analysis showed that blood mixed with bile). After four days, the drain became dry and the abdominal catheter was removed. The patient received 2 units of packed RBCs and she maintained her vital signs and hemoglobin around $8.5 \mathrm{~g} / \mathrm{dl}$. Computed tomography scan of abdomen revealed large left hepatic lobe subcapsular hematoma $16 \times 7 \times 12 \mathrm{~cm}$ with no active bleeding causing compression of the left hepatic vein with capsule tension (Figure 2).

The patient was kept on broad spectrum antibiotics. On the third day, she complained of abdominal discomfort and vomiting which could be attributed to compression of the stomach and proximal duodenum by the hematoma as shown in (Figure 3).

On the basis of the laboratory, clinical, and hemodynamic parameters the patient was hemodynamically stable. She was managed conservatively with only ultrasound guided drained of abdominal collection and no any radiological or surgical intervention needed for the hematoma. Her follow-up CT scan of abdomen at day- 8 showed most of the hematoma organized (Figure 4). The patient discharged home day20 of hospitalization with close follow-up in outpatient department.

\section{DISCUSSION}

Subcapsular hepatic hematoma is a rare unexpected and potentially life-threatening complication after ERCP. It was firstly described by Ortega et al. [4] in 2000 who diagnosed subcapsular hematoma in 81-year-old male with abdominal pain after ERCP for common bile duct stone.

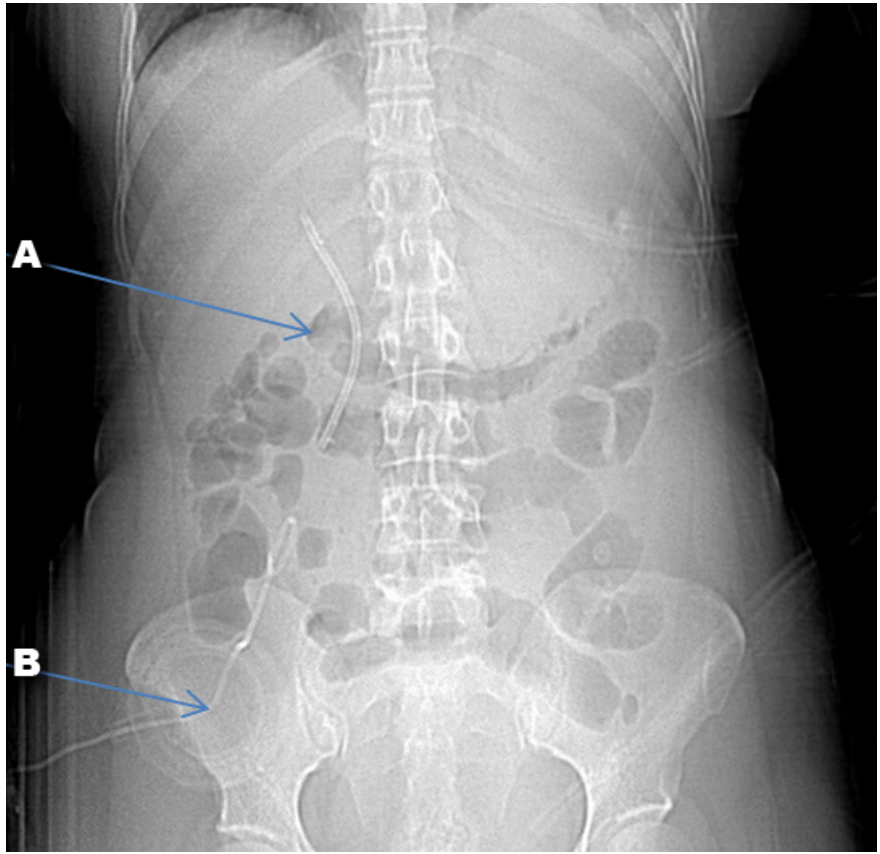

Figure 1: Plain computed tomography scan showing (A) Plastic common bile duct stone stent (B) Lobe and intra-abdominal drain in place.

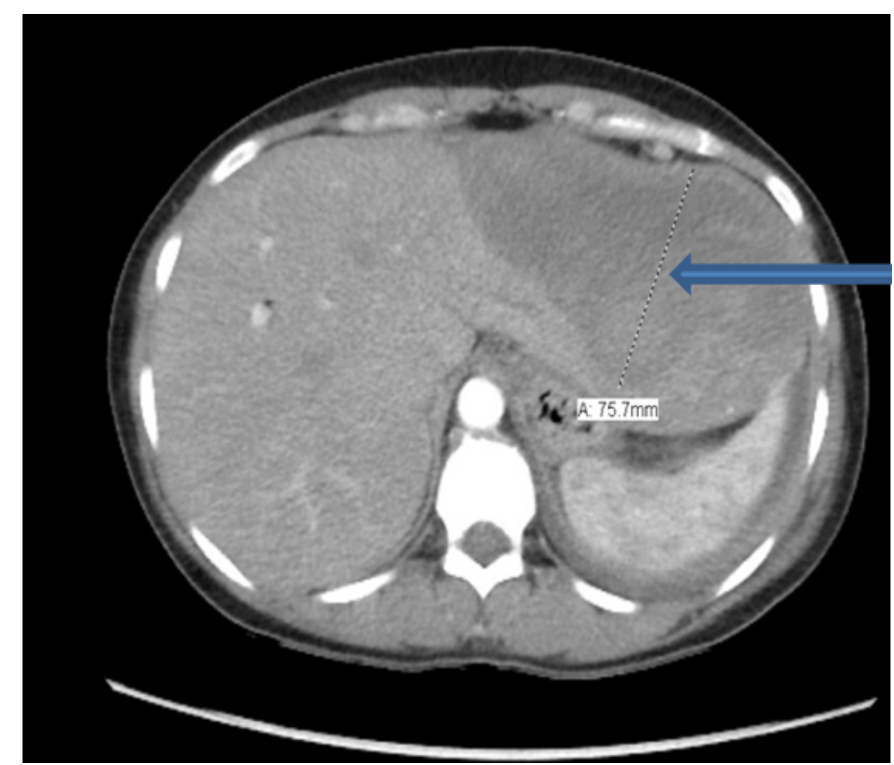

Figure 2: Computed tomography scan of abdomen showing left liver subcapsular hematoma (arrow).

The etiology of the hematoma is not entirely clear. Most of the authors claimed that it is caused by rupture of small caliber vessels due to the guidewire trauma [5-7]. In our case, guidewire is the most probable cause as it appears in (Figure 5).

Abdominal pain associated with hypotension and tachycardia after ERCP should raise the suspicion of intrahepatic bleeding with capsule distension. Different symptoms are described in literature abdominal pain (91\%), hypotension (39.1\%), anemia (39.1\%), fever (21.7\%) and peritonism (13\%) [8]. In this case, the 


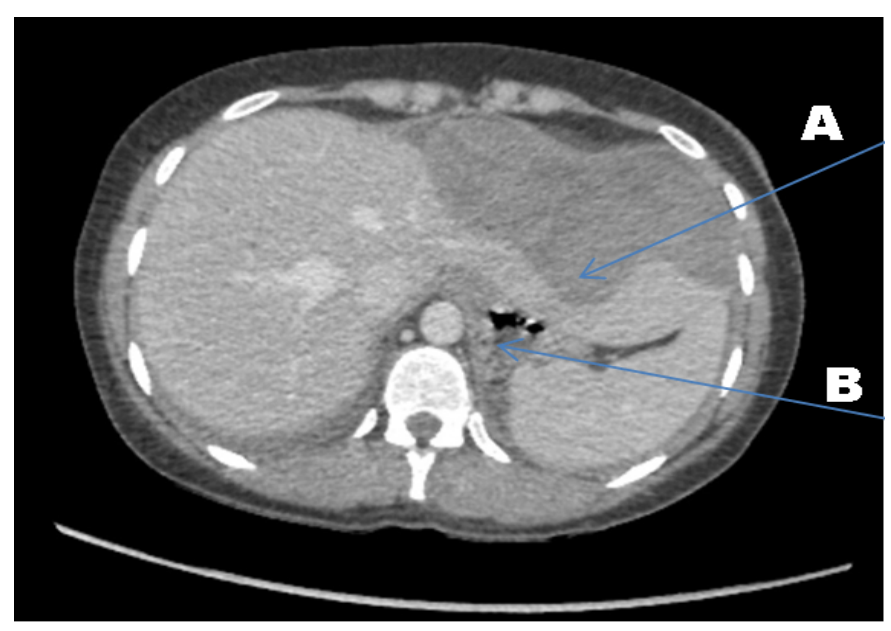

Figure 3: Hematoma reaching to the left abdominal wall causing compression of the stomach and proximal small bowel. (A) Liver subcapsular hematoma causing compression of stomach, (B) Compressed stomach.

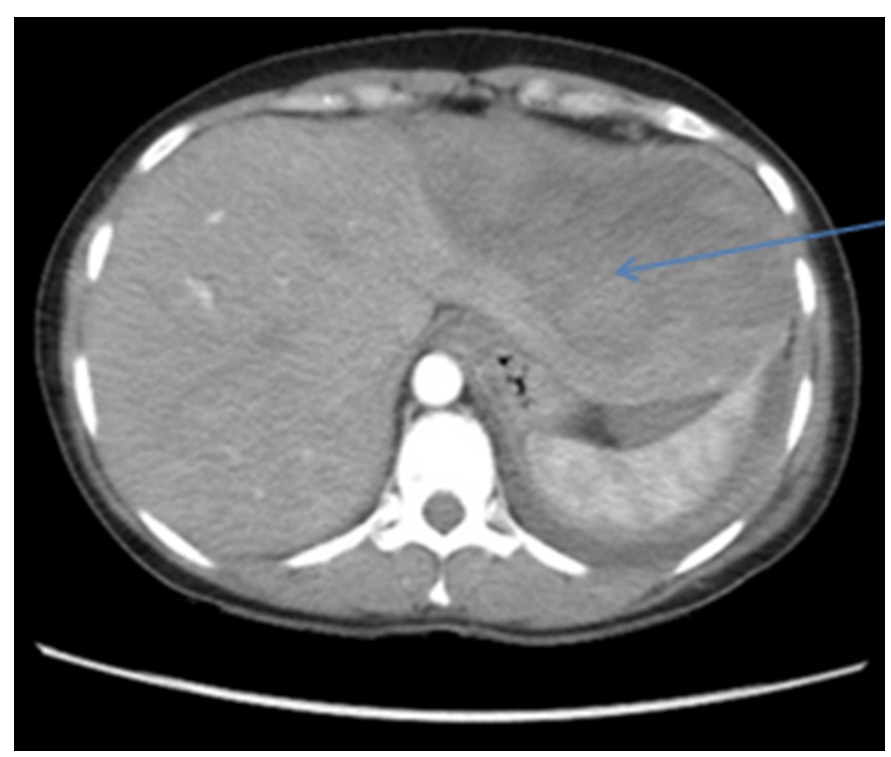

Figure 4: Abdominal computed tomography scan day-8 showing heterogeneous hematoma due to clot formation.

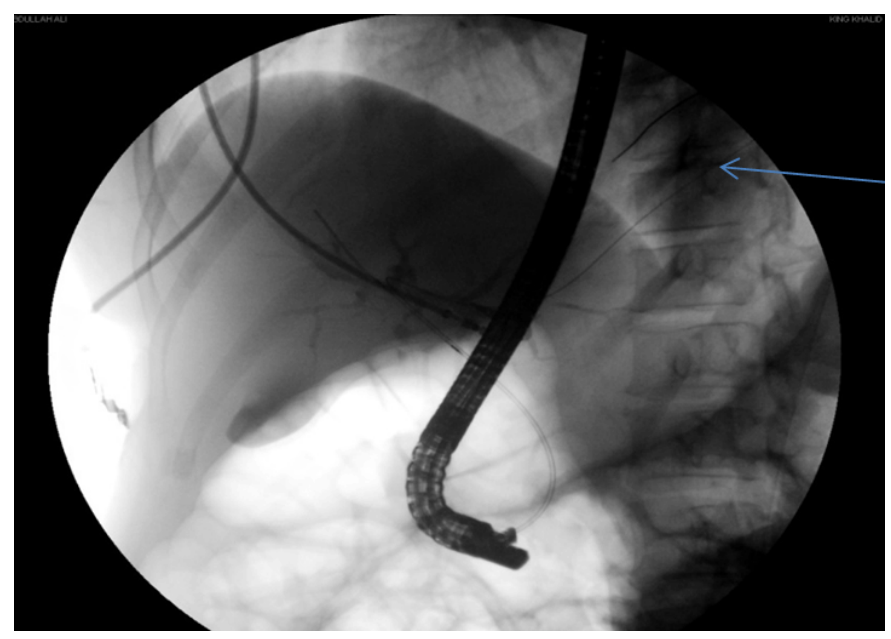

Figure 5: Deeply inserted endoscopic retrograde cholangiopancreatography (ERCP) guidewire 0.035 inch into left liver lobe. patient has epigastric pain, anemia, tachycardia and vomiting which could be attributed to stomach and duodenal compression. Computed tomography scan and ultrasound are the gold standard radiological modalities for diagnosis and surveillance of this complication [9].

No laboratory test provide reliable indicators of the development of a subcapsular hepatic hematoma, except for a decrease in the hemoglobin level [10, 11]. The management is conservative for most of the cases as we did in our case. As the Glisson's capsule of the liverconfined the hematoma and prevents more bleeding. However large hematomas may require percutaneous drainage for symptomatic relief $[7,12]$. The management of 25 cases reported up to now (41.5\% cases conservative, percutaneous drainage (25\%), embolization (21\%), and surgical intervention only in three cases $12.5 \%$ ). As the guidewire may be sources of infection we recommend prophylactic broad spectrum antibiotics for these patients to prevent hematoma infection and abscess formation. In our case, hematoma did not increase and hemodynamics of the patient remained stable, so she did not require embolization or surgical intervention.

In the case of hemodynamic instability, different therapeutic approaches including minimally invasive radiological intervention such as selective vessels embolization showed high success rates [13]. Surgical approach consist of hematoma evacuation, local hemostasis with electrocoagulation or hemostatic devices, or packing in case of massive hemorrhage [14].

\section{CONCLUSION}

Rare endoscopic retrograde cholangiopancreatography (ERCP) complications like liver subcapsular hematoma must be kept in mind if the patient complains of right upper quadrant pain or develops hemodynamic instability. Treatment is mostly conservative. As the guidewire may be sources of infection we suggest prophylactic antibiotic because hematoma is liable to get infection and abscess formation, with follow-up by serial computed tomography scans. Hepatic artery embolization and surgery should be performed early in case of hemodynamic instability or increasing size of hematoma. We concluded that guidewire injury of the hepatic vessels is the most probably causative agent and avoidance of deep insertion of the guidewire may decrease the risk of such catastrophic complication.

$$
* * * * * * * * *
$$

\section{Author Contributions}

Alzubaidi A.M. - Substantial contributions to conception and design, Acquisition of data, Analysis and interpretation of data, Drafting the article, Revising it critically for important intellectual content, Final approval of the version to be published 
Alshadadi A.A. - Acquisition of data, Revising it critically for important intellectual content, Final approval of the version to be published

Atta M.F. - Analysis and interpretation of data, Drafting the article, Revising it critically for important intellectual content, Final approval of the version to be published Alsareii S.A. - Analysis and interpretation of data, Drafting the article, Revising it critically for important intellectual content, Final approval of the version to be published

\section{Guarantor}

The corresponding author is the guarantor of submission.

\section{Conflict of Interest}

Authors declare no conflict of interest.

\section{Copyright}

(C) 2017 Alzubaidi A.M. et al. This article is distributed under the terms of Creative Commons Attribution License which permits unrestricted use, distribution and reproduction in any medium provided the original author(s) and original publisher are properly credited. Please see the copyright policy on the journal website for more information.

\section{REFERENCES}

1. Zizzo M, Lanaia A, Barbieri I, Zaghi C, Bonilauri S. Subcapsular hepatic hematoma after endoscopic retrograde cholangiopancreatography: A case report and review of literature. Medicine (Baltimore) 2015 Jul;94(26):e1041.

2. Cotton PB, Garrow DA, Gallagher J, Romagnuolo J. Risk factors for complications after ERCP: A multivariate analysis of 11,497 procedures over 12 years. Gastrointest Endosc 2009 Jul;70(1):80-8.

3. Abdel Aziz AM, Lehman GA. Pancreatitis after endoscopic retrograde cholangio-pancreatography. World J Gastroenterol 2007 May 21;13(19):2655-68.

4. Ortega Deballon P, Fernández Lobato R, García Septiem J, Nieves Vázquez MA, Martínez Santos C, Moreno Azcoita M. Liver hematoma following endoscopic retrograde cholangiopancreatography (ERCP). Surg Endosc 200o Aug;14(8):767.

5. Orellana F, Irarrazaval J, Galindo J, et al. Subcapsular hepatic hematoma post ERCP: A rare or an underdiagnosed complication? Endoscopy 2012;44 Suppl 2 UCTN:E108-9.

6. Petit-Laurent F, Scalone O, Penigaud M, Barbeys J. Subcapsular hepatic hematoma after endoscopic retrograde cholangiopancreatography: Case report and literature review. [Article in French]. Gastroenterol Clin Biol 2007 Aug-Sep;31(8-9 Pt 1):750-2.

7. Bhati CS, Inston N, Wigmore SJ. Subcapsular intrahepatic hematoma: An unusual complication of ERCP. Endoscopy 2007 Feb;39 Suppl 1:E150.

8. Zappa MA, Aiolfi A, Antonini I, Musolino CD, Porta A. Subcapsular hepatic haematoma of the right lobe following endoscopic retrograde cholangiopancreatography: Case report and literature review. World J Gastroenterol 2016 May 7;22(17):4411-5.

9. Priego P, Rodríguez G, Mena A, et al. Subcapsular liver hematoma after ERCP. [Article in Spanish]. Rev Esp Enferm Dig 2007 Jan;99(1):53-4.

10. Cárdenas A, Crespo G, Balderramo D, Bordas JP, Sendino O, Llach J. Subcapsular liver hematoma after endoscopic retrograde cholangiopancreatography in a liver transplant recipient. Ann Hepatol 2008 OctDec;7(4):386-8.

11. Klímová K, Suárez CP, Asanza CG, Peña AM, Arregui EC, Alonso AH. Subcapsular hepatic hematoma after ERCP: A case report and revision of literature. Scientific Research 2014;3(3):161-66.

12. Fei BY, Li CH. Subcapsular hepatic haematoma after endoscopic retrograde cholangiopancreatography: An unusual case. World J Gastroenterol 2013 Mar 7;19(9):1502-4.

13. Solmaz A, Gülçiçek OB, Erçetin C, et al. Subcapsular hepatic hematoma following endoscopic retrograde cholangiopancreatography. J Case Reports 2016 Jan 30;6(1):40-3.

14. González-López R, García-Cano E, EspinosaGonzález O, Cruz-Salgado Á, Montiel-Jarquin ÁJ, Hernández-Zamora V. Surgical treatment for liver haematoma following endoscopic retrograde cholangiopancreatography: An unusual case. [Article in Spanish]. Cir Cir 2015 Nov-Dec;83(6):506-9.
Access full text article on other devices

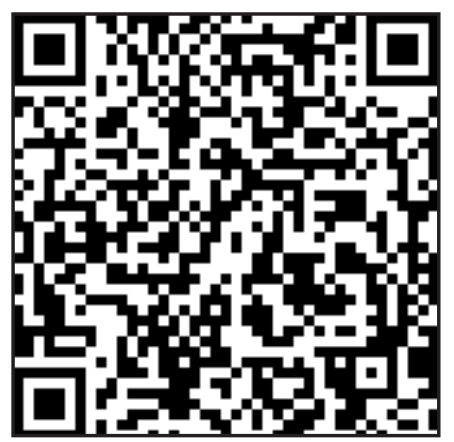

Access PDF of article on other devices

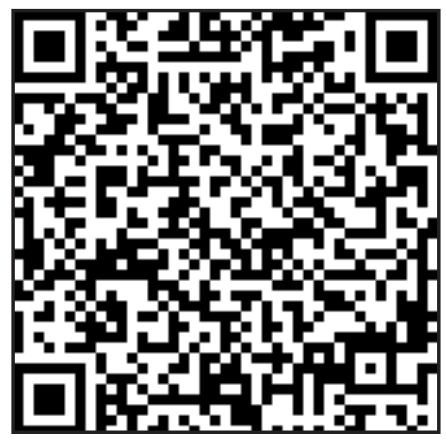

